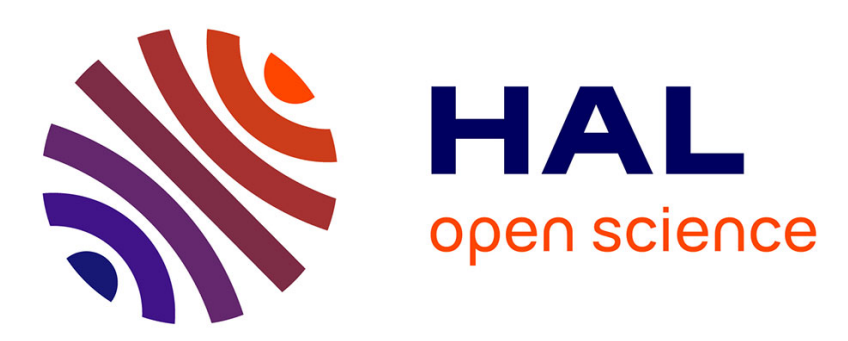

\title{
Extensions of Island Biogeography Theory predict the scaling of functional trait composition with habitat area and isolation
}

\author{
Claire Jacquet, David Mouillot, Michel Kulbicki, Dominique Gravel
}

\section{- To cite this version:}

Claire Jacquet, David Mouillot, Michel Kulbicki, Dominique Gravel. Extensions of Island Biogeography Theory predict the scaling of functional trait composition with habitat area and isolation. Ecology Letters, 2017, 20 (2), pp.135-146. 10.1111/ele.12716 . hal-01927194

\author{
HAL Id: hal-01927194 \\ https://hal.science/hal-01927194
}

Submitted on 22 Nov 2018

HAL is a multi-disciplinary open access archive for the deposit and dissemination of scientific research documents, whether they are published or not. The documents may come from teaching and research institutions in France or abroad, or from public or private research centers.
L'archive ouverte pluridisciplinaire HAL, est destinée au dépôt et à la diffusion de documents scientifiques de niveau recherche, publiés ou non, émanant des établissements d'enseignement et de recherche français ou étrangers, des laboratoires publics ou privés. 


\section{IDEA AND}

\section{PERSPECTIVE Extensions of Island Biogeography Theory predict the scaling of functional trait composition with habitat area and isolation}

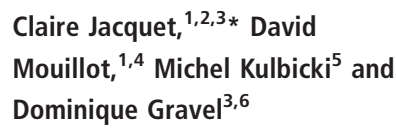

Claire Jacquet, ${ }^{1,2,3 *}$ David Dominique Gravel ${ }^{3,6}$

\begin{abstract}
The Theory of Island Biogeography (TIB) predicts how area and isolation influence species richness equilibrium on insular habitats. However, the TIB remains silent about functional trait composition and provides no information on the scaling of functional diversity with area, an observation that is now documented in many systems. To fill this gap, we develop a probabilistic approach to predict the distribution of a trait as a function of habitat area and isolation, extending the TIB beyond the traditional species-area relationship. We compare model predictions to the body-size distribution of piscivorous and herbivorous fishes found on tropical reefs worldwide. We find that small and isolated reefs have a higher proportion of large-sized species than large and connected reefs. We also find that knowledge of species body-size and trophic position improves the predictions of fish occupancy on tropical reefs, supporting both the allometric and trophic theory of island biogeography. The integration of functional ecology to island biogeography is broadly applicable to any functional traits and provides a general probabilistic approach to study the scaling of trait distribution with habitat area and isolation.
\end{abstract}

\section{Keywords}

Allometric theory, body-size, food web, island biogeography, tropical reefs.

\section{INTRODUCTION}

Human activities have caused widespread degradation of natural landscapes through habitat destruction, fragmentation and homogenisation (Haddad et al. 2015; Newbold et al. 2015). Understanding the effect of habitat area and isolation on biodiversity is therefore a central question in ecology and conservation (Tscharntke et al. 2012; Newbold et al. 2015). Although most of the early studies on biogeography have focused on the ecological processes determining species richness distribution (e.g. Arrhenius 1921; MacArthur \& Wilson 1963), other aspects of biodiversity, such as functional or phylogenetic diversity, are increasingly investigated (Gaston \& Blackburn 2000; Whittaker et al. 2014; Mazel et al. 2015). Body-size distribution within species assemblages is also a critical aspect of biodiversity since productivity, energy flows and biomass storage are all size-based constrained (McMahon 1973; Peters \& Wassenberg 1983; Brown et al. 2004; Woodward et al. 2005; Brose et al. 2006; Vucic-Pestic et al. 2010). Hence, species body-size has been successfully used to parameterise food web models (Yodzis \& Innes 1992; Williams \& Martinez 2000; Allesina et al. 2008; Williams et al. 2010;
Gravel et al. 2013). This study aims to develop a framework bringing new insights upon the effect of habitat area and isolation on the local distribution of functional traits, with an application to the body-size distribution of tropical reef fishes worldwide.

The frequency distribution of species body-size in a local assemblage is not a random sample of the regional species body-size distribution (Gaston \& Blackburn 2000). It has been demonstrated that the right skewed species body-size distribution of North and South American mammals, observed at the continental scale, becomes progressively flatter until being nearly uniform with decreasing area (Brown \& Nicoletto 1991; Blackburn \& Gaston 1994; Marquet \& Cofre 1999; Bakker \& Kelt 2000). Other studies, focusing on the relationship between extreme body-size and habitat area, show that, in general, smaller habitat patches have fewer taxa of extreme sizes (Marquet \& Taper 1998; Burness et al. 2001; Okie \& Brown 2009; Millien \& Gonzalez 2011). In marine ecosystems, the scaling of larval-stage duration and fish mobility with body-size has been hypothesised to primarily drive the global variation of species body-size distribution across assemblages (Connell 1983; Mora et al. 2003; Jetz et al. 2004; Rooney

\footnotetext{
${ }^{1}$ UMR 9190 MARBEC (MARine Biodiversity, Exploitation and Conservation), Université de Montpellier, Place Eugène Bataillon - bât 24 - CC093, 34095, Montpellier Cedex 05, France

${ }^{2}$ Département de biologie, chimie et géographie, Université du Québec à Rimouski, 300 Allée des Ursulines, Rimouski, QC G5L 3A1, Canada

${ }^{3}$ Quebec Center for Biodiversity Science, Montréal, QC, Canada

${ }^{4}$ Australian Research Council Centre of Excellence for Coral Reef Studies,

James Cook University, Townsville, QLD 4811, Australia
}

\footnotetext{
5IRD UMR "Entropie", Labex"Corail", Université de Perpignan, 66000, Perpignan, France

${ }^{6}$ Chaire de recherche en Écologie intégrative, Département de biologie, Université de Sherbrooke, 2500 Boulevard Université, Sherbrooke, QC J1K 2R1, Canada

*Correspondence: E-mail: claire.jacquet@uqar.ca
} 
et al. 2008; Luiz et al. 2013; Stier et al. 2014; Nash et al. 2015). Despite this long-lasting interest in size-based approaches, we still lack a theoretical framework explaining species body-size distribution in assemblages as a function of habitat area and isolation.

Here, we propose a simple and general approach to predict the distribution of a trait in a local assemblage as a function of habitat area and isolation. The main idea is that the local trait distribution corresponds to a sub-sample of the regional species pool, which is influenced by various ecological processes. We use this approach to derive how the mean and the standard deviation of species body-size distribution are expected to scale with island area and isolation. We consider islands as a general representation of isolated systems, such as lakes, ponds, forest fragments or coral reefs, surrounded by a desert of unsuitable habitat (Diamond 1975; Losos \& Ricklefs 2009; Warren et al. 2015). We develop two process-based models of island biogeography to determine the influence of species dispersal potential, vulnerability to extinction and trophic position on the variation of body-size distribution across islands, along a gradient of area and isolation. Then, we compare theoretical predictions to the empirical distributions of body-size in fish assemblages across 134 tropical reefs of various area and isolation. We finally highlight the importance of considering trophic position to explain the global variation of body-size distribution in reef fish assemblages.

\section{CONCEPTUAL FRAMEWORK}

\section{Probabilistic estimation of local trait distribution}

A local assemblage, composed of $S$ species, is a sub-sample of a regional pool composed of $R$ species, whose composition is determined by various ecological mechanisms. The trait distribution of this sub-sample can be expressed in the following way: let the random variable $X_{i}$ indicate the occurrence of species $i$ in a given island or local assemblage, with $X_{i}=0$ when species $i$ is absent and $X_{i}=1$ when present. The probability of picking a species $i$ with a trait value $T_{i}$ in this local assemblage is:

$P\left(X_{i}, T_{i}\right)=P\left(X_{i}=1 \mid T_{i}\right) \times P\left(T_{i}\right)$

where $P\left(T_{i}\right)$ corresponds to the probability of observing a species with trait value $T_{i}$ in the regional pool, which depends on the moments of the regional trait probability distribution $f(T)$. $P\left(X_{i}=1 \mid T_{i}\right)$ is the occupancy of species $i$, that is the probability for species $i$ to occupy the island knowing its trait value $T_{i}$. This probability expresses the influence of ecological processes on species occupancy and varies according to the ecological hypotheses tested by the model.

We then derive the density function of trait $T$, observed in a local assemblage as:

$g_{T}=P(T \mid X=1)=\frac{P(X=1 \mid T) \times f(T)}{P(X)}$

where $P(X)=S / R$. This illustrates how the regional trait distribution $f(T)$ and ecological processes, determining $P\left(X_{i}=1 \mid T_{i}\right)$, shape the species trait distributions of local assemblages (Fig. 1). The strength of this approach is to clearly distinguish the influence of both ecological processes and the composition of the regional pool on the local trait distribution $g(T)$. The scaling of species occupancy with the studied trait is the key to predict its local distribution (Fig. 1). In the upcoming sections, we provide an application of this framework to species body-size, denoted $M$, in the context of island biogeography theory.

\section{Theory of island biogeography (TIB)}

The Theory of Island Biogeography (TIB) provides a processbased explanation to the general observation that larger islands have more species than smaller ones, and islands closer to the mainland have more species than isolated ones (MacArthur \& Wilson 1963; Losos \& Ricklefs 2009). Local species richness, i.e. within an island, results from the balance between colonisation and extinction dynamics. Colonisation rate $c$, that is species' colonisation probability per unit time, is assumed inversely proportional to the distance to the mainland hosting the regional species pool. Extinction rate $e$ (species extinction probability per unit time) is assumed inversely proportional to island area, as this geographical characteristic directly affects population size and thus species sensitivity to demographic stochasticity (Hanski 1989). In the TIB, species interactions have no impact on colonisation and extinction rates. All species are assumed to be functionally equivalent and have the same probability of occupying the island irrespective of their body-size $M_{i}$. Consequently, $P\left(X_{i}=1 \mid\right.$ $\left.M_{i}\right)=P\left(X_{i}=1\right)=c /(c+e)$ (Gravel et al. 2011) and the species body-size distribution in a local assemblage is a random sample of $S$ species drawn from the body-size probability distribution of the regional pool: $g(M)=f(M)$.

\section{Allometric theory of island biogeography (ATIB)}

The TIB assumes that all species are equally influenced by island area and isolation in their probability of occurrence. However, body-size is likely to influence both colonisation and extinction rates. Owing to the negative relationship between species abundance and body-size (Damuth 1981; Nee et al. 1991; Blackburn 1999; White et al. 2007), extinction rate has been hypothesised to be positively correlated with bodysize. Consequently, we should consider $e_{i} \propto M_{i}^{b}$, meaning that large-bodied species will be more impacted by decreasing island area than small-bodied species. The link between species extinction rate and body-size is, however, not straightforward with multiple factors acting together, such as minimum viable population size, dependence to habitat complexity or diet generality (Gaston \& Blackburn 2000; Graham et al. 2011). For example, some studies proposed that intermediate body-sized species could be the less prone to extinction in small areas as they are more generalists than small species and have higher densities than large species, leading to a Ushaped relationship between extinction rate and body-size: $e_{i} \propto-M_{i}\left(\frac{x-M_{i}}{x}\right)$ (Brown et al. 1993; Marquet \& Taper 1998; Okie \& Brown 2009).

In contrast, the scaling of colonisation rate with body-size is supported by many empirical studies (Peters \& Wassenberg 1983; Wieters et al. 2008). In marine systems, home range, 
(a)

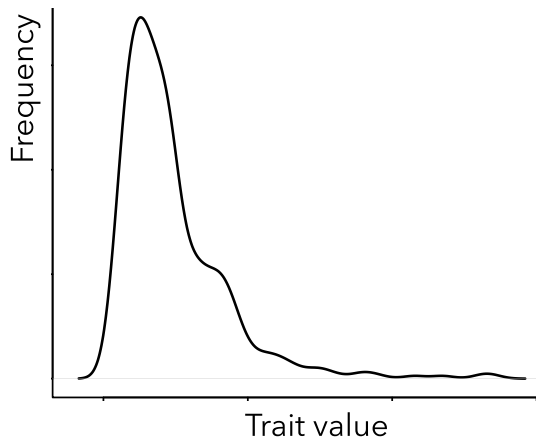

Regional trait distribution (b)

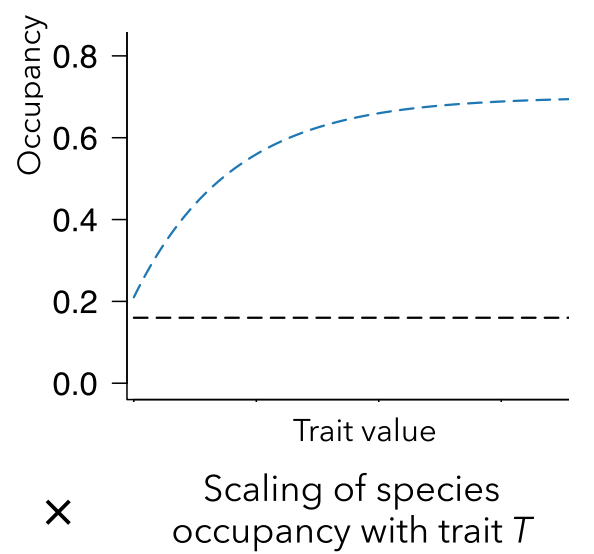

(c)

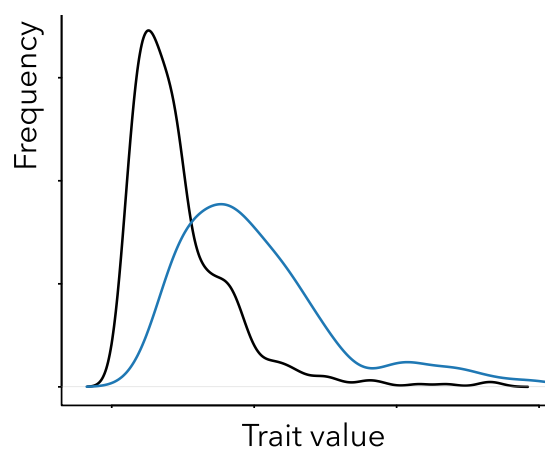

$=$

Figure 1 Conceptual framework. The regional distribution of trait $T$ (left panel) and the scaling of species occupancy with $T$ (middle panel) determine species trait distribution in the local assemblage (right panel). If species occupancy is independent of trait $T$ (b, black dotted line), the local trait distribution will be similar to the regional trait distribution (c, in black). If species occupancy increases with trait $T$, the mean of the local trait distribution (c, in blue) will be greater than in the regional pool.

pelagic larval duration, number of larvae produced per adult, mobility and diet generality increase with fish body-size (Mora et al. 2003; Luiz et al. 2013; Nash et al. 2015). The positive relationship between species body-size and their dispersal potential is thought to primarily influence the body-size distribution of reef fishes at the biogeographical scale (Cornell \& Karlson 2000; Mora et al. 2003; Luiz et al. 2013; Stier et al. 2014).

The scaling of extinction and colonisation rates with bodysize can be easily integrated into the TIB, leading to an Allometric Theory of Island Biogeography (ATIB). A general model of the equilibrium occurrence probability should be species-specific, with $P\left(X_{i}=1 \mid M_{i}\right)=c_{i} /\left(c_{i}+e_{i}\right)$. The net effect of area and isolation on the resulting distribution will be dependent on the functions specified for $c_{i}$ and $e_{i}$. In the following analyses, we make different assumptions regarding the scaling of extinction rate with body-size, leading to three versions of the ATIB that we consider representative of most situations: extinction rate is independent of body-size $\left(\mathrm{ATIB}_{\mathrm{H} 0}\right)$, extinction rate increases with body size $\left(\mathrm{ATIB}_{\mathrm{H} 1}\right)$ and intermediate body-sized species are less prone to extinction than small and large species $\left(\mathrm{ATIB}_{\mathrm{H} 2}\right)$.

\section{Allometric and trophic theory of island biogeography (ATTIB)}

Another plausible hypothesis is that colonisation and extinction dynamics are influenced by resource availability (Holt 2002, 2009; Cirtwill \& Stouffer 2015). Under this assumption, species spatial dynamics depend not only on island characteristics and species traits but also on the composition of the local assemblage. The Trophic Theory of Island Biogeography is an extension of the TIB that takes into account the effect of trophic interactions on colonisation and extinction rates (Gravel et al. 2011). It relies on two assumptions translating the concept of a bottom-up sequential dependency of predators on their prey (Holt 1997, 2009): (1) a predator species colonising a local assemblage will persist only if at least one of its potential prey species is present and (2) a predator species losing its last potential prey in a local assemblage goes extinct (Gravel et al. 2011). Diet breadth is therefore a key trait influencing predator occurrence, with generalist species more likely to find prey species at colonisation and persist then after. This theory predicts that consumers at the top of the food web have a lower occupancy than basal species as they rely on the presence of species at each intermediate trophic level. The TTIB is a first step toward the integration of resource availability constraints to species spatial dynamics. The hypothesis of "at least one prey species present" should be considered as an easily computable way to represent resource availability rather than a strict assumption related to the presence/absence of a particular prey species.

We build an Allometric and Trophic Theory of Island Biogeography (ATTIB) that combines the ATIB and the TTIB. The equilibrium occurrence probability is $P\left(X_{p}=1 \mid M_{p}\right)=c_{p} /$ $\left(c_{p}+e_{p}\right)$ for predatory species, where colonisation and extinction rates $c_{p}$ and $e_{p}$ depend not only on the body-size of predator species $p$ but also on its diet breadth $g_{p}$ and its trophic position with respect to primary resources. Note that the spatial dynamics of basal species (noted $b$ ), located at the bottom of the food web and feeding on primary resources, are independent of assemblage composition and correspond to the ATIB: $P\left(X_{b}=1 \mid M_{b}\right)=c_{b} /\left(c_{b}+e_{b}\right)$.

The ATTIB requires an a priori knowledge of the regional food web structure (who eats whom). This kind of information is only available for a limited number of species and remains challenging to collect over large geographic scales or for species-rich assemblages. We used predator-prey allometric relationships observed in marine ecosystems and the method presented in Gravel et al. (2013) to parameterise the niche model of food web structure (Williams \& Martinez 2000). The niche model assigns to each consumer species a feeding range on a niche axis that can overlap with itself (allowing cannibalism), generating realistic food web structure at least for marine fishes (Gravel et al. 2013). Body-size is the niche position of every species and the optimal prey size is determined by the regression of prey size against predator 
size, and the range by quantile regressions (section 1 of Supporting Information). The parameters of the niche model were derived from data on marine food webs (Fig. S3, Gravel et al. 2013; Barnes et al. 2010) and are presented in Table S1.

The diet breadth of a predatory species $i$ depends on the probability of feeding on the species present in the regional species pool. Let the random variable $L_{i j}$ indicate the occurrence of a trophic interaction between species $i$ and species $j$, with $L_{i j}$ $=0$ when species do not interact and $L_{i j}=1$ when species $i$ can feed on species $j$. The expected number of prey items can then be expressed from the species body-size distribution as:

$g_{i}=\sum_{j=1}^{R}\left[P\left(L_{i j}=1 \mid M_{i}, M_{j}\right) \times P\left(M_{j}\right)\right]$

where $P\left(L_{i j}=1 \mid M_{i}, M_{j}\right)$ is the probability that species $i$ feeds on species $j$ knowing their body-sizes $M_{i}$ and $M_{j}$ while $P\left(M_{j}\right)$ corresponds to the probability to observe a species with bodysize $M_{j}$ in the regional pool (Williams et al. 2010; Gravel et al. 2013; Bartomeus et al. 2016). The ATTIB thus predicts the interactive effect of biogeography and trophic position on the species body-size distribution in local assemblages from the relationship between diet breadth and body-size of species composing the regional pool. We consider three versions of the ATTIB assuming different relationships between extinction rate and body-size $\left(\mathrm{ATTIB}_{\mathrm{H} 0}, \mathrm{ATTIB}_{\mathrm{H} 1}\right.$ and $\left.\mathrm{ATTIB}_{\mathrm{H} 2}\right)$.

\section{THEORETICAL PREDICTIONS}

\section{From species occupancy to local body-size distribution}

The TIB, the ATIB and the ATTIB predict different sizeoccupancy relationships and consequently different body-size distributions $g(M)$. We use species richness, the mean and the standard deviation (SD) of $g(M)$ to describe the local bodysize distribution. We then run stochastic simulations to study the effect of island area and isolation on these metrics and compare the predictions of the TIB, the ATIB and the ATTIB.

\section{Simulations}

We consider a regional species pool composed of 200 species. The body-size $M_{i}$ of any species $i$ is randomly drawn from a log-normal distribution $f(M)$ of mean $\mu$ and standard deviation $\sigma$. This distribution roughly represents the observed distributions at large spatial scale (Cohen et al. 1993; Brown 1995; Allen et al. 2006). Mean and SD are derived from the global body-size distribution of tropical reef-associated piscivorous fishes (Kulbicki et al. 2013; Parravicini et al. 2013 - see next section). We ran simulations for 2500 pairs of $c$ and $e$ that vary between 0.01 and 0.99 . Simulations were run over 1000 time steps. All the model parameters are presented in section 1 of Supporting Information (Table S1, Figs S1-S3).

We use a discrete time stochastic version of the ATTIB to simulate the dynamics of species occupancy in local assemblages. The stochastic version of the model was found to better fit empirical data because it takes into account the effect of trophic level and the way that each species is connected to the food web (Gravel et al. 2011). At each time step, a predator species absent from the local assemblage colonises it with a probability $c_{p}$ if there is at least one prey or cannot otherwise. A predator species present in the local assemblage goes extinct with a probability $e_{p}$. Further, a predator species losing its last prey species during a time step goes automatically extinct. The probability that a basal species colonises the local assemblage or goes extinct is $c_{b}$ and $e_{b}$, respectively, irrespective of the assemblage composition. We consider that herbivorous species are not food limited and consequently have the dynamics of basal species. Herbivorous species make half of the regional species pool.

\section{Island area and isolation shape species body-size distribution}

As predicted by the classic TIB, we find that species richness increases with island area (Fig. 2a) and decreases with island isolation (Fig. 2b) using the ATIB and the ATTIB. We then explore the relationships between island characteristics and species body-size distribution in local assemblages. Under the TIB, the expected body-size distribution in assemblages has the same mean and $\mathrm{SD}$ as in the regional species pool (Fig. 2c,d). The three versions of the ATIB predict a decrease in mean body-size with island area and an increase with island isolation (Fig. 2c,d, in red). The effects of island area and isolation are stronger for $\mathrm{ATIB}_{\mathrm{H} 2}$, in which the scaling of extinction rate with body-size is U-shaped, and weaker when extinction rate increases with body-size $\left(\mathrm{ATIB}_{\mathrm{H} 1}\right)$. The variation (SD) of species body-size within assemblages is not strongly influenced by island area or isolation (Fig. 2e,f, in red, $1.04<\sigma<1.08$ ). Under the ATTIB, the regional food web is characterised by a positive relationship between bodysize and diet breadth $g_{p}$, which determines the occupancy of predatory species $P\left(X_{p} \mid M_{p}\right)$. Large predatory species have a higher probability of finding prey species on a small and isolated island, and persist then after, than small predatory species. At the assemblage level, the ATTIB predicts that island area and isolation bias the local body-size distribution of predatory species towards larger and less variable body-sizes on small or isolated islands. This is illustrated in Fig. 2c,d where mean body-size of predatory species decreases with area and increases with isolation. On small or isolated islands, the variation (SD) of body-size is lower than expected from the regional species pool, suggesting a lower proportion of extreme-sized predatory species as island geographic constrains increase (Fig. 2e,f, in blue, $0.88<\sigma<1.04$ ). The three versions of the ATTIB predict similar effects of island area and isolation on the body-size distribution of local assemblages.

\section{APPLICATION TO TROPICAL REEF FISHES}

\section{Empirical data and statistical tests}

We investigate the influence of area and isolation of tropical reefs on the mean and SD of fish body-size distribution in local assemblages. We then downscale our analysis at the species-level and study the relative contribution of reef characteristics (area and isolation), body-size and trophic position on 
(a)

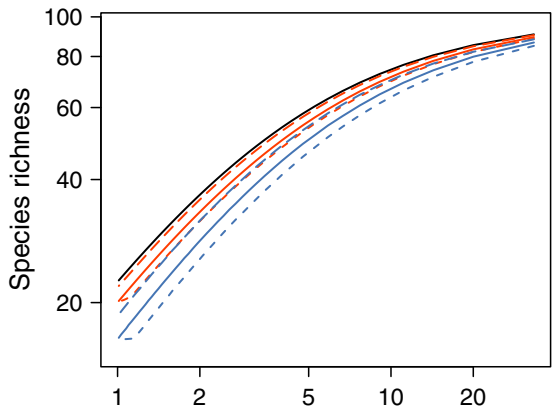

(c)

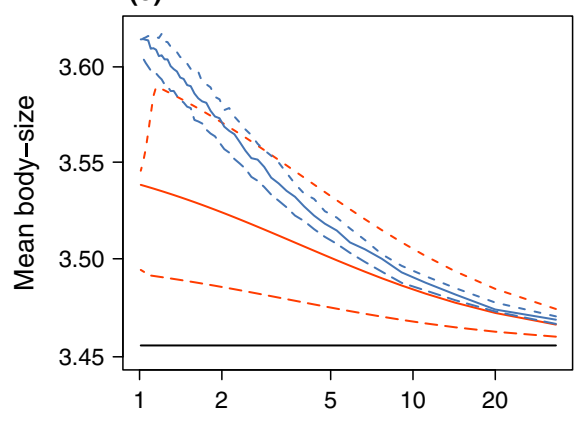

(e)

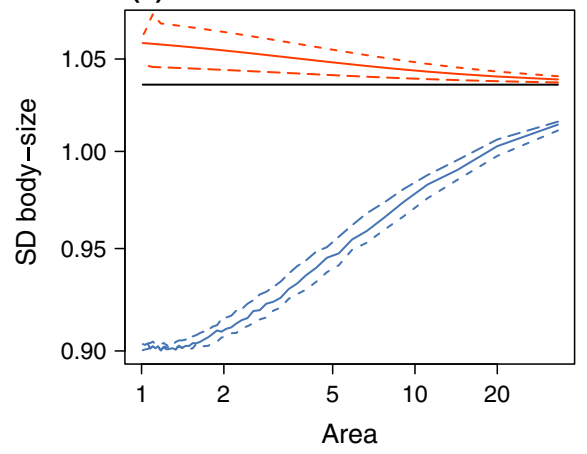

(b)

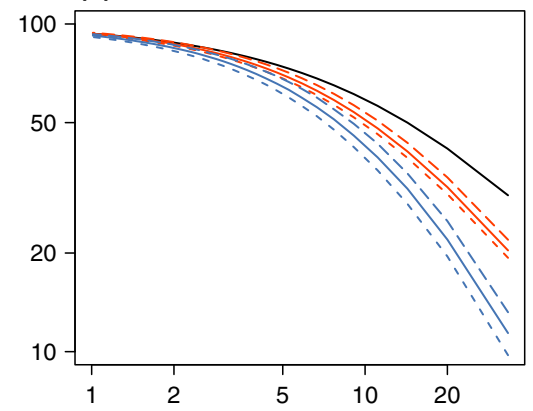

(d)

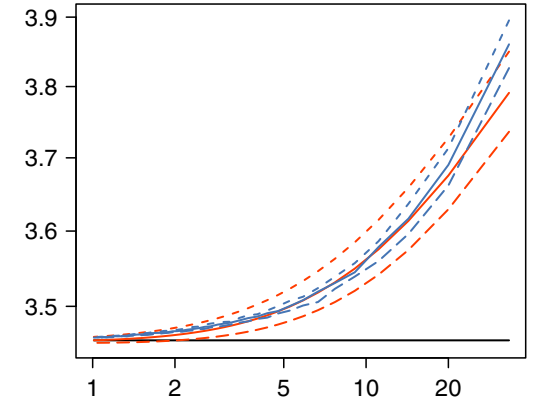

(f)

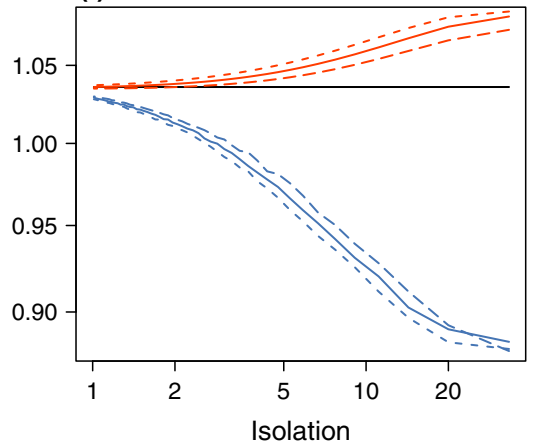

Figure 2 Influence of island area and isolation on species body-size distribution predicted by the TIB (in black) and different versions of the ATIB and the ATTIB. Red lines correspond to the ATIB and blue lines to the ATTIB. Full lines correspond to $\mathrm{H}_{0}$ (extinction rate independent of body-size), wide dotted lines to $\mathrm{H}_{1}$ (extinction rate increases with body-size) and small dotted lines to $\mathrm{H}_{2}$ (U-shaped relationship). Island area corresponds to $1 / \mathrm{e}$ where e is species extinction rate and colonisation rate is fixed to 0.13 . Island isolation corresponds to $1 / \mathrm{c}$ and extinction rate is fixed to 0.13 . (a and b) Relationship between species richness $S$ at equilibrium and habitat area or isolation in local assemblages. (c and d) Relationship between average body-size at equilibrium and island area (c) or isolation (d) in local assemblages. (e and f) Relationship between standard deviation of body-size at equilibrium and island area (e) or isolation (f) in local assemblages.

species occurrences across tropical reefs. We use a published database of 991 piscivorous and herbivorous tropical reefassociated fishes and their presence/absence in 134 locations worldwide (Kulbicki et al. 2013; Parravicini et al. 2013). These locations correspond to tropical reefs in areas with a minimum monthly sea surface temperature of $17^{\circ} \mathrm{C}$. Twentytwo sites are located in the Atlantic Ocean, 40 in the Indian Ocean, 63 in the Pacific Ocean and 9 in the Tropical Eastern Pacific. The database is composed of information from published studies, regional checklists, monographs and reports. We use total reef area $\left(\mathrm{km}^{2}\right)$ to estimate reef area of each location (range: $6.3 \times 10^{-3} \mathrm{~km}^{2}$ to $19166 \mathrm{~km}^{2}$, mean: $917 \mathrm{~km}^{2}$, Coral Reef Millennium Census project, Andréfouët et al. 2006). We use the relative distance of each location to other patches of reef habitat to quantify reef isolation $(\mathrm{km})$ using a nearest neighbour approach: for each location, the mean distance from the location to the 10 nearest reef patches is calculated (range: 209-1708 km, mean: $527 \mathrm{~km}$, Parravicini et al. 2013). The database contains average body-size and occurrence of 652 piscivorous fishes and 339 herbivorous fishes (feeding on undefined organic material, turf or filamentous algae). Body-size ranges between 3 and $400 \mathrm{~cm}$ for piscivorous fishes and between 2.4 and $120 \mathrm{~cm}$ for herbivorous fishes. In order to distinguish the predictions of the ATIB and the ATTIB, we choose to study species with marked different diets only (i.e. piscivorous vs. herbivorous species). The ATTIB considers omnivores in a similar way to herbivores because they are little constrained by prey distribution; we however removed them from the analysis to maximise the contrast between types of diet. 
We test three predictions at the assemblage-level derived from the models of island biogeography: (1) species richness is influenced by reef area and isolation (derived from the TIB, ATIB and ATTIB), (2) mean fish body-size decreases with area and increases with isolation (derived from the ATIB and ATTIB), (3) variation (SD) of body-size of piscivorous fishes increases with area and decreases with isolation (derived from the ATTIB). We use ordinary least-squares regressions on logtransformed data to characterise the relationships between species richness and (1) area and (2) isolation. We build second-order regression models and use a stepwise algorithm based on Akaike's Information Criterion to determine which regressions fit the data best (i.e. linear or quadratic relationships). We use the same method to characterise the relationships between the mean and the SD of fish body-size and (1) area or (2) isolation. We also build multiple polynomial regression models to evaluate the relative contribution of reef area, reef isolation, their quadratic form and their interaction on the body-size distribution of reef fish assemblages.

At the species-level, we focus on the following predictions: (1) species occurrence (i.e. occupancy) is influenced by reef area and isolation (derived from the TIB, ATIB and ATTIB), (2) occupancy is influenced by species body-size (derived from the ATIB and ATTIB) and (3) occupancy is influenced by species trophic position (TTIB, ATTIB). We build corresponding logistic regression models to test these predictions.
We compare their capacity to predict species occupancy based on (1) island characteristics, (2) body-size and (3) trophic position (predatory or basal species) using Akaike's Information Criterion corrected for small sample size (AICc; Burnham \& Anderson 2002). Models with the lowest AICc values were considered to provide the best fit.

\section{Global variations across reef fish assemblages}

Tropical reef locations contain on average 121 piscivorous and 48 herbivorous species. Local species richness varies between 15 and 294 species for piscivorous fishes (Fig. 3a), and between 6 and 124 species for herbivorous ones (Fig. S4a). Species richness of both piscivorous and herbivorous fishes increases with reef area and decreases with reef isolation (Fig. 4a,b), consistently with the predictions of the TIB, ATIB and ATTIB (Fig. 2a,b). We then analyse the relationships between reef characteristics and mean body-size within fish assemblages. On small and isolated reefs, the mean bodysize of piscivorous and herbivorous fishes is significantly higher than on large and connected reefs (Fig. 4c,d). Reef area and isolation are negatively correlated (Spearman's rank correlation: $r=-0.42, P=3.8 \times 10^{-7}$, Fig. S5), and their interaction contributes to explain the variation of mean bodysize across assemblages for herbivorous fishes only (Table 1). Further, we find that the proportion of piscivorous fishes (a)

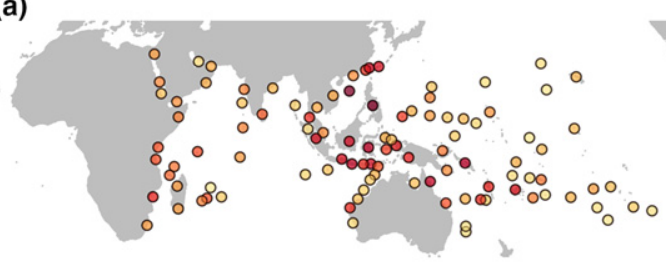

(b)

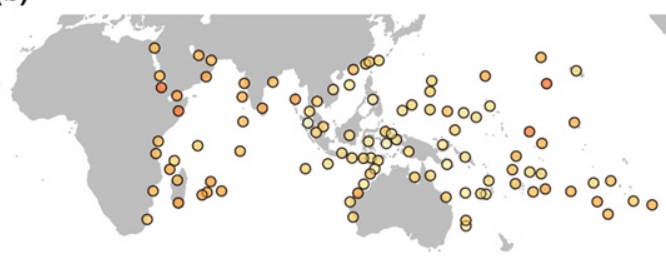

(c)

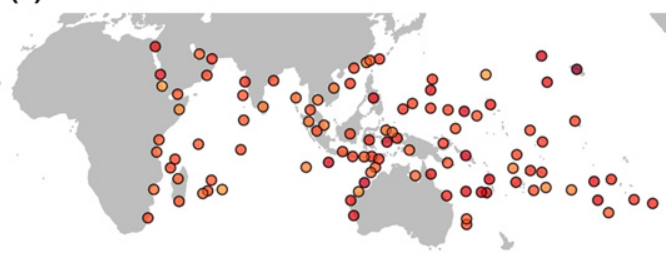

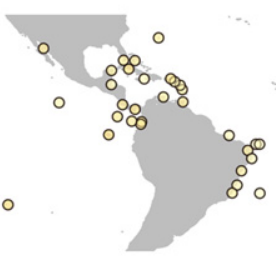

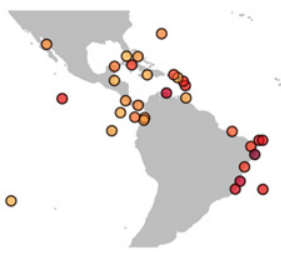

$S$

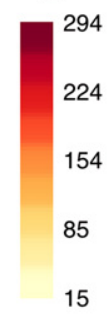

$\mu$
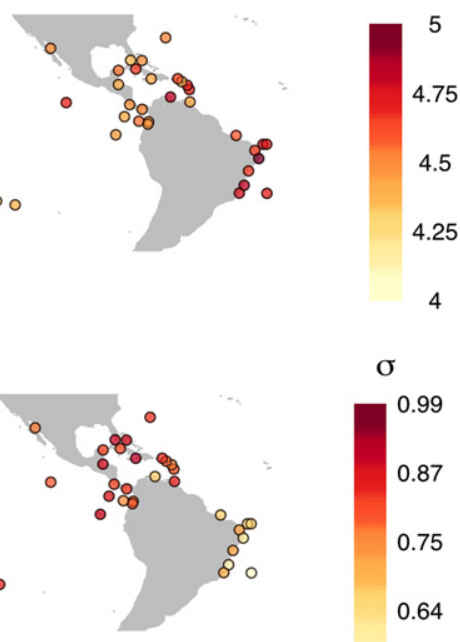

$\sigma$

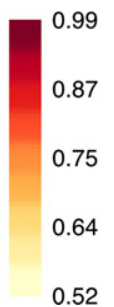

Figure 3 Global variation of body-size distribution in piscivorous fish assemblages observed across 134 locations on tropical reefs. Circle colour is proportional to the three metrics describing piscivorous fish assemblages at each location: species richness (a), mean body-size (b) and standard deviation (c) of species body-size. 


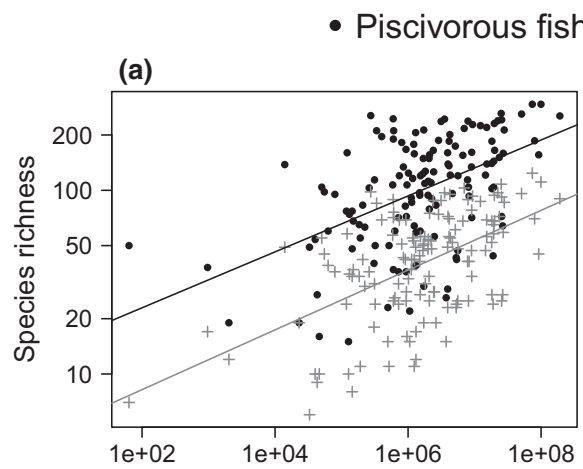

\section{+ Herbivorous fish}

(b)

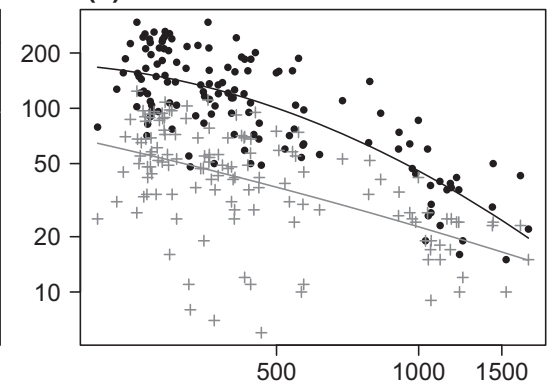

(c)

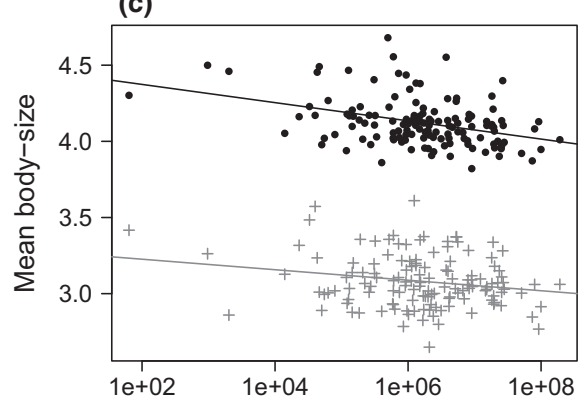

(d)

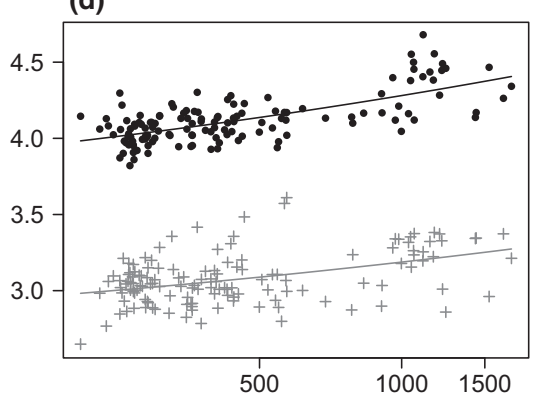

(e)
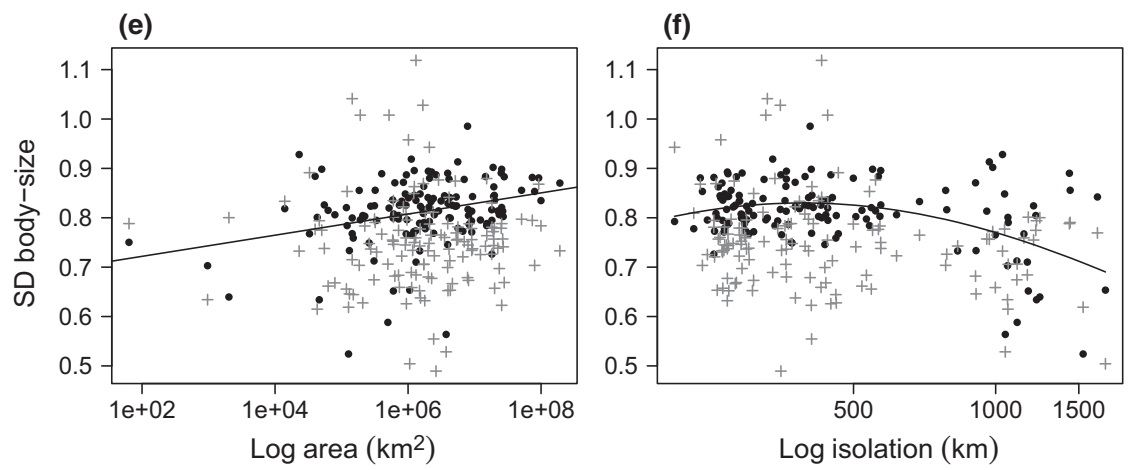

Figure 4 (a) Relationship between species richness of piscivores (black circles) and herbivores (grey crosses), and reef area observed in 134 tropical reef locations $\left(\right.$ in $\left.\mathrm{km}^{2}\right)$, least-square ordinary regression statistics for piscivorous species $\left(R^{2}=0.26, P\right.$-value $\left.=10^{-10}\right)$ and for herbivorous species $\left(R^{2}=0.31\right.$, $P$-value $=10^{-12}$ ). b) Relationship between species richness and reef isolation (relative proximity to the 10 nearest reefs; piscivorous species: $R^{2}=0.61, P$ value $\leq 10^{-16}$, herbivorous species: $R^{2}=0.31, P$-value $=10^{-12}$ ). c) Relationship between reef area and mean $\mu$ of species body-size (piscivorous species: $P$-value $=10^{-6}, R^{2}=0.14$, herbivorous species: $R^{2}=0.04, P$-value $=0.02$ ). (d) Relationship between reef isolation and mean $\mu$ of species body-size (piscivorous species: $P$-value $\leq 10^{-16}, R^{2}=0.47$, herbivorous species: $P$-value $=10^{-7}, R^{2}=0.19$ ). (e) Relationship between reef area and standard deviation $\sigma$ of species body-size (piscivorous species: $R^{2}=0.1, P$-value $=10^{-4}$, herbivorous species: $R^{2}=0, P$-value $=0.89$ ). f) Relationship between reef isolation and standard deviation $\sigma$ species body-size (piscivorous species: $R^{2}=0.20, P$-value $\leq 10^{-7}$, herbivorous species: $R^{2}=0.03, P$-value $=0.06$ )

smaller than $30 \mathrm{~cm}$ decreases on small and isolated reefs, while the proportion of piscivorous fishes larger than $80 \mathrm{~cm}$ increases (Fig. 5a,c). These observed relationships for piscivorous and herbivorous fishes are consistent with the ATIB and the ATTIB.

We observe a positive relationship between reef area and the SD of body-size among piscivorous fishes but not for herbivorous ones (Fig. 4e, Table 1). As reef isolation increases, the SD of body-size decreases for piscivorous fishes (Fig. 4f). We also observe a relationship between reef area or isolation and extreme sizes of piscivorous fishes. The maximum fish size increases with reef area while the minimum size decreases (Fig. 5b). Conversely, the range between the minimum and the maximum fish size decreases with reef isolation (Fig. 5d).
The SD of herbivorous fish body-sizes is not influenced by reef area or isolation, which supports the predictions of the ATTIB (Table 1).

At the species level, we find that knowledge of reef area and isolation improves the predictions of species occurrences, as the logistic regression model integrating these explanatory variables has a significantly lower corrected Akaike's Information Criterion (AICc) than the null expectation (Table 2). Additionally, we find that logistic regression models integrating species body-size and trophic position (piscivore or herbivore) have significantly lower AICc than the models based on reef area and isolation only (Table 2). We conclude that body-size and trophic position are key to predict fish species occupancy on tropical reefs, according to the ATTIB. 
Table 1 Analyses of variance for second-order polynomial regression models accounting for $\log _{10}($ reef $\operatorname{area}), \log _{10}$ (reef isolation) and their interaction

\begin{tabular}{|c|c|c|c|c|c|c|}
\hline \multirow[b]{2}{*}{ Variable } & \multicolumn{5}{|c|}{ F-value ( $P$-value $)$} & \multirow[b]{2}{*}{$R^{2}$} \\
\hline & Area & Isolation & Area $^{2}$ & Isolation $^{2}$ & A $\times I$ & \\
\hline S pisc. & $110.87\left(10^{-16}\right)$ & $172.19\left(10^{-16}\right)$ & $0.06(0.8)$ & $16.45\left(10^{-5}\right)$ & $0.1(0.75)$ & 0.69 \\
\hline S herb. & $75.68\left(10^{-14}\right)$ & $36.71\left(10^{-8}\right)$ & $0.3(0.58)$ & $2.78(0.1)$ & $1.78(0.19)$ & 0.46 \\
\hline Mean BS pisc. & $38.44\left(10^{-9}\right)$ & $91.9\left(<10^{-16}\right)$ & $1.56(0.2)$ & $4.77(0.03)$ & $0.37(0.54)$ & 0.5 \\
\hline Mean BS herb. & $6.73(0.01)$ & $25.51\left(10^{-7}\right)$ & $1.35(0.25)$ & $0.06(0.8)$ & $12.1(0.001)$ & 0.24 \\
\hline SD BS pisc. & $17.06\left(10^{-5}\right)$ & $14.38\left(10^{-4}\right)$ & $0.06(0.8)$ & $15\left(10^{-4}\right)$ & $2.6(0.1)$ & 0.25 \\
\hline SD BS herb. & $0(0.99)$ & $6.35(0.02)$ & $0(0.99)$ & $0.2(0.65)$ & $1.57(0.21)$ & 0.02 \\
\hline
\end{tabular}

Response variables are species richness, mean and standard deviation (SD) of $\log _{10}$ (body-size) for piscivorous and herbivorous fishes. F-values in bold illustrate a significant effect of the explanatory variable $(P$-value $<0.01)$.

(a)

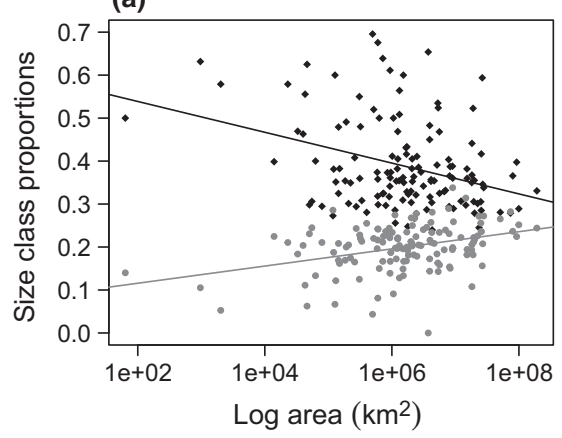

(c)

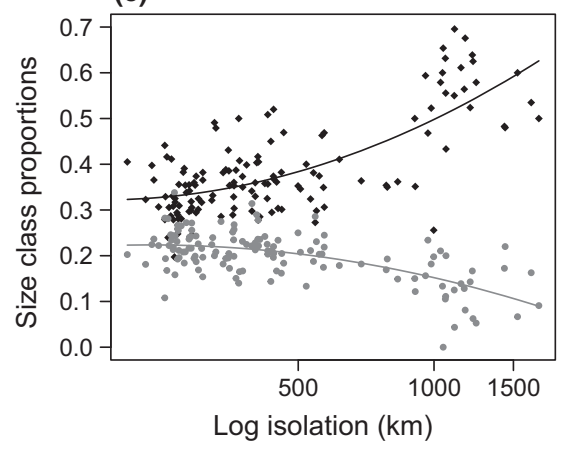

- Maximum body size

- Minimum body size

(b)

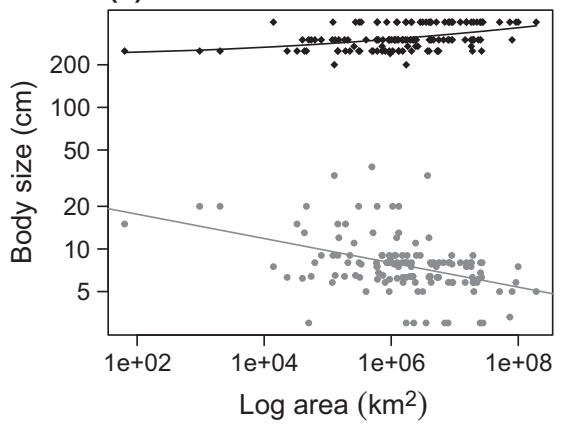

(d)

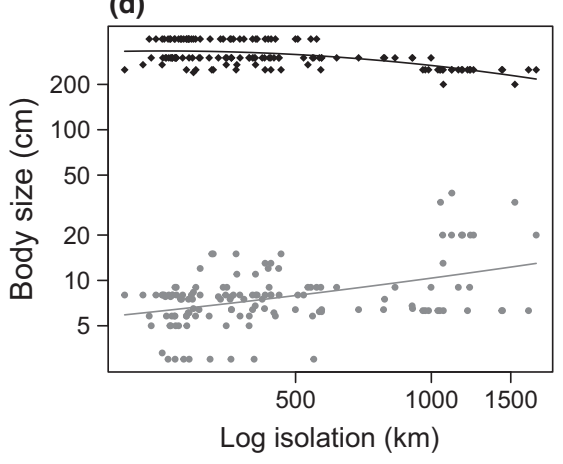

Figure 5 (a) Relationship between reef area and body-size classes observed in piscivorous fish assemblages: proportion of piscivorous fishes < 30 cm $\left(R^{2}=0.12, P\right.$-value $\left.=10^{-5}\right)$ and proportion of piscivorous fishes $>80 \mathrm{~cm}\left(R^{2}=0.11, P\right.$-value $\left.=10^{-5}\right)$. (b) Relationship between reef area and extreme body-sizes observed in piscivorous fish assemblages: minimal body-size $\left(R^{2}=0.18, P\right.$-value $\left.=10^{-7}\right)$ and maximal body-size $\left(R^{2}=0.15, P\right.$-value $\left.=10^{-6}\right)$. c) Relationship between reef isolation and body-size classes observed in piscivorous fish assemblages: proportion of piscivorous fishes $<30 \mathrm{~cm}\left(R^{2}=0.35, P\right.$ value $\left.=10^{-14}\right)$ and proportion of piscivorous fishes $>80 \mathrm{~cm}\left(R^{2}=0.51, P\right.$-value $\left.<10^{-16}\right)$. (d) Relationship between reef isolation and extreme body-sizes observed in piscivorous fish assemblages: minimal body-size $\left(R^{2}=0.18, P\right.$-value $\left.<10^{-7}\right)$ and maximal body-size $\left(R^{2}=0.3, P\right.$-value $\left.=10^{-11}\right)$. Reef area, reef isolation and body-size are on a logarithmic scale. The interaction of reef area and isolation has not significant effect on these relationships.

\section{DISCUSSION}

\section{A step forward in the biogeography of species body-size}

Based on the theory of island biogeography, we develop a theoretical framework that links species occupancy to body-size. We then study the predictions made by two models of island biogeography: (1) the ATIB, where colonisation and extinction rates scale with body-size and (2) the ATTIB, which further assumes that diet generality and trophic position scale with body size. Contrary to the null expectation of the traditional model of island biogeography (TIB), our models provide a process-based explanation to the observed body-size distribution at a locality that can differ from a random sample of the regional species pool.

The allometric scaling theory proposed by Marquet \& Taper (1998) predicts a positive power-law relationship between maximum species body-size and land area. This relationship has been reported for mammals, birds and reptiles (Marquet \& Taper 1998; Burness et al. 2001; Okie \& Brown 2009; Millien \& Gonzalez 2011). According to these authors, 
Table 2 Corrected Akaike's Information Criterion (AICc) for the different logistic regression models based on the occurrence of 991 species over 134 locations

\begin{tabular}{lll}
\hline Model & GLM formula & AIC $_{\mathrm{c}}$ \\
\hline Random sampling & $\operatorname{glm}(X \sim 1)$ & 121542 \\
TIB & $\operatorname{glm}(X \sim A \times I)$ & 116747 \\
TTIB & $\operatorname{glm}(X \sim A \times I \times G)^{2}$ & 116238 \\
ATIB & $\operatorname{glm}(X \sim A \times I \times M)^{2}$ & 114887 \\
ATTIB & $\operatorname{glm}(X \sim A \times I \times \boldsymbol{M} \times \boldsymbol{G})^{\mathbf{3}}$ & $\mathbf{1 1 4} \mathbf{4 7 3}$ \\
\hline
\end{tabular}

The variable $X$ indicates species occurrence, with $X_{i}=0$ when species $i$ is absent from the reef and $X_{i}=1$ when it is present. The random sampling model supposes that species are distributed randomly in each location. The explanatory variables of the TIB are island $A$, isolation $I$ and their interaction. The TTIB adds trophic position $G$ (piscivorous or herbivorous species) and its interactions with $A$ and $I$ as explanatory variables, while the ATIB adds body-size $M$ and its interactions. Finally, the explanatory variables of the ATTIB are island area, isolation, body-size, trophic position and all their interactions. The model with the lowest AICc value (in bold) is considered to fit the data best.

extreme-sized species have higher extinction rates than intermediate-sized species in smaller islands since their populations are approaching minimal viable population sizes. They hypothesise that intermediate-sized species are more generalist than small-sized species and have higher densities than largesized species, thus preventing their stochastic extinctions in the smallest areas (Okie \& Brown 2009). Our observations show that the allometric theory also holds for tropical reef fishes, although extreme body-sizes only provide a partial picture of the influence of reef area on species body-size distribution. As illustrated in Fig. 5b, we find a positive relationship between maximum body-size and reef area that supports the allometric scaling theory. The relationship is however negative for the proportion of large-bodied piscivorous fishes (Fig. 5a), since mean body-size decreases with area (Fig 4c).

A positive relationship between species body-size and diet generality enhances the persistence of large-sized species on small and isolated islands. However, a regional food web in which small or medium-sized species feed on more prey items than large species would lead to a different relationship between body-size and occupancy (Fig. S6). Consequently, the trophic structure of the regional species pool could also influence the effect of insularity on the local body-size distribution.

\section{Implications for tropical reef fishes}

Fishes play key functional roles on tropical reefs (Bellwood et al. 2012; Bozec et al. 2016) and provide protein for several hundred million people, especially in the developing world (Teh et al. 2013). This provision of eatable biomass is not only promoted by fish species richness (Mora et al. 2011) but also by the diversity of fish traits (Duffy et al. 2016). The body-size spectrum or the distribution of body-size within fish assemblages has been recognised as a primary operative factor in determining ecosystem functioning and the production of biomass (Fisher et al. 2010).
The ATTIB provides a mechanistic explanation to the variability of body-size distributions across reef-associated fish assemblages reported by previous studies (Stier et al. 2014; Kulbicki et al. 2015). We find that small and isolated reefs support a higher mean fish body-size than large and connected ones. In tropical reef ecosystems, a relatively flat slope $\left(\alpha_{1}=0.44-0.47\right)$ for the allometric relationship between predator and prey body-size has been reported (Barnes et al. 2010), in agreement with observations across some of our reefs (Fig. S3). The consequent scaling of diet generality with bodysize is a possible driver of occupancy of reef-associated piscivorous fishes, explaining why fewer species of extreme sizes are observed in species-poor tropical reef assemblages. The ATTIB is also supported by the maximum likelihood analysis for logistic regression models, showing that knowledge of fish body-size and trophic position improves the predictions of species occupancy.

The influence of diet generality on the ability of fishes to colonise isolated islands could be due to alternative processes related to body-size, a trait that is well-known to correlate with many aspects of life history and demography (Brown et al. 2004; Woodward et al. 2005; Brose et al. 2016). For instance, small-bodied species are more dependent on reef habitat complexity (Graham et al. 2011) compared to largebodied species, which are more generalist and can thus colonise small and isolated islands. In addition, large-bodied species would be at advantage when confronted to major environmental changes (bleaching events or climate stress) as they can reach more favourable environments (including resource availability) owing to a wider home range and higher dispersal ability.

\section{Generality of the framework}

The Allometric and Trophic Theory of Island Biogeography assumes that: (1) the frequency distribution of species bodysize is log-normal, (2) generalists are more likely to find prey species than specialists and (3) all islands share the same source of species (island-mainland approach to metacommunity dynamics). We assume a log-normal distribution in our simulations, which corresponds to the regional body-size distribution observed in our dataset (section 1 of Supporting Information). Several studies report a highly skewed distribution for species body-size, meaning that the distribution remains skewed after a logarithmic transformation (Etienne \& Olff 2004; Smith \& Lyons 2013). Supplementary simulations using a highly skewed body-size distribution for the regional species pool nonetheless show similar results than the ones reported in the main analysis (Fig. S7).

The ATTIB further assumes that species with large diets are more likely to find resources than specialists. If specialists preferentially feed upon widely distributed species while generalists preferentially feed upon narrowly distributed species, this assumption could be violated (Srinivasan et al. 2007). The stochastic version of the ATTIB takes into account this phenomenon, since a specialist feeding on prey with high occupancy will be more likely to persist than a predator feeding on rare prey species. As a consequence, the theory also predicts that consumers at the top of the food web have a lower 
occupancy than basal species as they rely on the presence of species at each intermediate trophic levels.

Finally, the Theory of Island Biogeography is a particular case of the metacommunity theory (Leibold et al. 2004), as it assumes a unidirectional flow of migration, from the mainland to the islands. Consequently, all islands share the same species pool, represented by the same body-size distribution. In more complex and realistic spatial structures, migration flows between islands are bidirectional. Determining the effect of migration from various patches on a local body-size distribution would require further development of the ATTIB. In a meta-community system, we expect that the body-size distribution of the source pool is itself dynamic and responds to island characteristics. If an island is connected to large islands occupied by many species, the body-size distribution of its migration source will be very different in comparison to an island connected to small and species poor islands.

The intraspecific variations in body-size are not captured by our theory, thus ignoring ontogeny and evolutionary dynamics (such as the ones expected by the island rule - Foster 1964; Faurby \& Svenning 2016). Body-size has a positive effect on dispersal abilities through all the ontogenetic stages of tropical reef fishes. However, for a given taxonomic group, we may observe opposite effects of body-size on colonisation rate through ontogenetic growth.

In this study, we applied the ATIB and the ATTIB to tropical reef fishes and the scaling of colonisation and extinction rates were defined from knowledge on this particular taxonomic group. The scaling of body-size with extinction and colonisation rates is, however, not universal and is expected to differ between (1) taxonomic groups (2) habitat types (3) the matrix surrounding habitat patches and (4) the geographic structure of patches. These factors must be considered when applying this framework to other insular systems such as forest fragments, mountain tops, lakes or ponds. We assumed a positive relationship between colonisation rate and body-size because all the life-history traits promoting colonisation are positively correlated with fish body-size, such as fecundity, home range, mobility or diet generality (Luiz et al. 2013; Kulbicki et al. 2015; Nash et al. 2015). Inferring this scaling is less straightforward in taxonomic groups where these traits scale differently with body-size. For example, fecundity decreases with body-size for birds and mammals while mobility increases (Marquet et al. 2005). On the other hand, the average population density of reef fishes is far higher than for terrestrial herbivorous mammals or birds for instance (Damuth 1981; Juanes 1986; Marquet et al. 1990; Kulbicki et al. 2015; Barneche et al. 2016). Hence, the smallest area required to sustain a viable population should greatly differ between taxonomic groups and environmental conditions.

\section{CONCLUSION}

The amount of small and isolated habitat patches is expected to increase with ongoing habitat destruction and fragmentation, and a greater number of ecosystems are likely to suffer modifications in their structure and functioning (Haddad et al. 2015; Newbold et al. 2015). Here, we develop a theoretical framework, explaining the scaling of body-size with island area and isolation, which is flexible and can easily be applied to other functional traits. Several studies revealed a scaling of functional diversity with area (Mazel et al. 2014; Whittaker et al. 2014), thus providing expectations of functional and phylogenetic diversity loss following habitat destruction (Keil et al. 2015).

These studies are essentially descriptive and none of them provided process-based hypotheses to explain these observations. There are many alternative hypotheses, usually in line with a mechanistic explanation of the species-area relationship (e.g. heterogeneity area relationship, Kadmon \& Allouche 2007), but none of them have been rigorously tested. Our framework can facilitate such discriminant tests of hypotheses derived from the theory of island biogeography. Interestingly, our theory not only predicts the scaling of functional diversity with area and isolation, but it also proposes that some mean trait values can also consistently scale with these biogeographical constraints. It is also clear that the multivariate functional trait composition of species assemblages is related to food web structure (Gravel et al. 2016), thus challenging an extension of this framework to multiple traits at a time.

\section{ACKNOWLEDGEMENT}

We thank the CESAB, which enabled the creation of the reef fish data base through the GASPAR program, Valeriano Parravicini for his work on the reef fish database that facilitated empirical analyses and four anonymous reviewers for their detailed comments which significantly improved the manuscript. C.J. was supported by a grant from the Ministry of Higher Education and Research of France. Financial support was also provided by the Canada Research Chair program and a NSERC Discovery grant to DG. This study was supported by the ANR-FNS project "REEFISH" no 310030 E-164294 and by the SeaConnect project (Fondation TOTAL).

\section{STATEMENT OF AUTHORSHIP}

CJ, DM and DG designed research, conducted research and contributed to the analytical tools. MK participated in the data collection; CJ, DM and DG wrote the paper and all authors contributed to the edition.

\section{REFERENCES}

Allen, C.R., Garmestani, A.S., Havlicek, T.D., Marquet, P.A., Peterson, G.D., Restrepo, C. et al. (2006). Patterns in body mass distributions: sifting among alternative hypotheses. Ecol. Lett., 9, 630-643.

Allesina, S., Alonso, D. \& Pascual, M. (2008). A general model for food web structure. Science, 320, 658-661.

Andréfouët, S., Muller-karger, F.E., Robinson, J.A., Christine, J., Torrespulliza, D., Spraggins, S.A. et al. (2006). Global assessment of modern coral reef extent and diversity for regional science and management applications : a view from space. Proc. 10th Int. Coral Reef Symp., 2, 1732-1745.

Arrhenius, O. (1921). Species and area. J. Ecol., 9, 95.

Bakker, V.J. \& Kelt, D.A. (2000). Scale-dependent patterns in body size distributions of neotropical mammals. Ecology, 81, 3530-3547.

Barneche, D.R., Kulbicki, M., Floeter, S.R., Friedlander, A.M. \& Allen, A.P. (2016). Energetic and ecological constraints on population density 
of reef fishes. Proc. R. Soc. B Biol. Sci., 283, DOI: 10.1098/rspb.2015. 2186.

Barnes, C., Maxwell, D., Reuman, D.C. \& Jennings, S. (2010). Global patterns in predator-prey size relationships reveal size dependency of trophic transfer efficiency. Ecology, 91, 222-232.

Bartomeus, I., Gravel, D., Tylianakis, J.M., Aizen, M., Dickie, I. \& Bernard-Verdier, M. (2016). A common framework for identifying rules across different types of interactions. Funct. Ecol., DOI: 10.1111/13652435.12666.

Bellwood, D.R., Baird, A.H., Depczynski, M., Gonzalez-Cabello, A., Hoey, A.S., Lefèvre, C.D. et al. (2012). Coral recovery may not herald the return of fishes on damaged coral reefs. Oecologia, 170, 567-573.

Blackburn, T.M. \& Gaston, K.J. (1999). The Relationship between Animal Abundance and Body Size: A Review of the Mechanisms. Adv. Ecol. Res., 28, 181-210.

Blackburn, T.M. \& Gaston, K.J. (1994). Animal body size distributions: patterns, mechanisms and implications. Trends Ecol. Evol., 9, 471-474.

Bozec, Y.-M., O'Farrell, S., Bruggemann, J.H., Luckhurst, B.E. \& Mumby, P.J. (2016). Tradeoffs between fisheries harvest and the resilience of coral reefs. Proc. Natl. Acad. Sci., 113, 4536-4541.

Brose, U., Williams, R.J. \& Martinez, N. (2006). Allometric scaling enhances stability in complex food webs. Ecol. Lett., 9, 1228-1236.

Brose, U., Blanchard, J.L., Eklöf, A., Galiana, N., Hartvig, M., Hirt, M.R. et al. (2016). Predicting the consequences of species loss using size-structured biodiversity approaches. Biol. Rev., 49. DOI: 10.1111/ brv. 12250 .

Brown, J.H. (1995). Macroecology. The University of Chicago, Chicago.

Brown, J.H. \& Nicoletto, P. (1991). Spatial scaling of species composition: body masses of North American land mammals. Am. Nat., 138, 1478-1512.

Brown, J.H., Marquet, P.A. \& Taper, M.L. (1993). Evolution of body size : consequences of an energetic definition of fitness. Am. Nat., 142, 573-584.

Brown, J.H., Gillooly, J.F., Allen, A.P. \& Savage, V.M. (2004). Toward a metabolic theory of ecology. Ecology, 85, 1771-1789.

Burness, G.P., Diamond, J. \& Flannery, T. (2001). Dinosaurs, dragons, and dwarfs: the evolution of maximal body size. Proc. Natl Acad. Sci. USA, 98, 14518-14523.

Burnham, K.P. \& Anderson, D.R. (2002). Model Selection and MultiModel Inference: a Practical Information-Theoretic Approach. Springer, New York, 353pp.

Burnham, K.P. \& Anderson, D.R. (2004). Model Selection and Multimodel Inference. Springer New York, New York, NY.

Cirtwill, A.R. \& Stouffer, D.B. (2016). Knowledge of predator-prey interactions improves predictions of immigration and extinction in island biogeography. Glob. Ecol. Biogeogr., 25, 900-911.

Cohen, J.E., Pimm, S.L., Yodzis, P. \& Saldaña, J. (1993). Body sizes of animal predators and animal prey in food webs. J. Anim. Ecol., 62, 67-68.

Connell, J.H. (1983). On the prevalence and relative importance of interspecific competition: evidence from field experiments. Am. Nat., $122,661$.

Cornell, H.V. \& Karlson, R.H. (2000). Coral species richness: ecological versus biogeographical influences. Coral Reefs, 19, 37-49.

Damuth, J. (1981). Population density and body size in mammals. Nature, 290, 699-700.

Diamond, J. (1975). The island dilemma: Lessons of modern biogeographic studies for the design of natural reserves. Biol. Conserv., 7, 129-146.

Duffy, J.E., Lefcheck, J.S., Stuart-Smith, R.D., Navarrete, S.A. \& Edgar, G.J. (2016). Biodiversity enhances reef fish biomass and resistance to climate change. Proc. Natl Acad. Sci., 113, 6230-6235.

Etienne, R.S. \& Olff, H. (2004). How dispersal limitation shapes speciesbody size distributions in local communities. Am. Nat., 163, 69-83.

Faurby, S. \& Svenning, J.C. (2016). Resurrection of the island rule: human-driven extinctions have obscured a basic evolutionary pattern. Am. Nat., 187, 812-820.
Fisher, J., Frank, K. \& Leggett, W. (2010). Global variation in marine fish body size and its role in biodiversity-ecosystem functioning. Mar. Ecol. Prog. Ser., 405, 1-13.

Foster, J.B. (1964). Evolution of mammals on islands. Nature, 202, 234-235.

Gaston, K.J. \& Blackburn, T.M. (2000). Pattern and Process in Macroecology. Blackwell Science Ltd, Malden, MA, USA.

Graham, N.A.J., Chabanet, P., Evans, R.D., Jennings, S., Letourneur, Y., Aaron Macneil, M. et al. (2011). Extinction vulnerability of coral reef fishes. Ecol. Lett., 14, 341-348.

Gravel, D., Massol, F., Canard, E., Mouillot, D. \& Mouquet, N. (2011). Trophic theory of island biogeography. Ecol. Lett., 14, 1010-1016.

Gravel, D., Poisot, T., Albouy, C., Velez, L. \& Mouillot, D. (2013). Inferring food web structure from predator-prey body size relationships. Methods Ecol. Evol., 4, 1083-1090.

Gravel, D., Albouy, C. \& Thuiller, W. (2016). The meaning of functional trait composition of food webs for ecosystem functioning. Philos. Trans. R. Soc. B Biol. Sci., 371, 20150268, DOI: 10.1098/rstb.2015.0268.

Haddad, N.M., Brudvig, L. a, Clobert, J., Davies, K.F., Gonzalez, A., Holt, R.D., et al. (2015). Habitat fragmentation and its lasting impact on Earth's ecosystems. Sci. Adv., 1, e1500052. DOI: 10.1126/sciadv.1500052.

Hanski, I. (1989). Metapopulation dynamics: Does it help to have more of the same? Trends Ecol. Evol., 4, 113-114.

Holt, R.D. (1997). From Metapopulation Dynamics to Community Structure. In: Metapopulation Biology (eds. Hanski, I., Gilpin, M. E.). Elsevier, New York, pp. 149-164.

Holt, R.D. (2002). Food web in space: on the interplay of dynamic instability and spatial processes. Ecol. Res., 17, 261-273.

Holt, R.D. (2009). Toward a trophic island biogeography: reflections on the interface of island biogeography and food web ecology. In The theory of island biogeography revisited. (eds Losos, J., Ricklefs, R.). Princeton University Press, Princeton, pp. 143-185.

Jetz, W., Carbone, C., Fulford, J. \& Brown, J.H. (2004). The scaling of animal space use. Science, 306, 266-268.

Juanes, F. (1986). Population density and body size in birds. Am. Nat., 128, 921-929.

Kadmon, R. \& Allouche, O. (2007). Integrating the effects of area, isolation, and habitat heterogeneity on species diversity: a unification of island biogeography and niche theory. Am. Nat., 170, 443-454.

Keil, P., Storch, D. \& Jetz, W. (2015). On the decline of biodiversity due to area loss. Nat. Commun., 6, 8837.

Kulbicki, M., Parravicini, V., Bellwood, D.R., Arias-Gonzàlez, E., Chabanet, P., Floeter, S.R. et al. (2013). Global biogeography of reef fishes: a hierarchical quantitative delineation of regions. PLOS ONE, 8, e81847.

Kulbicki, M., Parravicini, V. \& Mouillot, D. (2015). Patterns and processes in reef fish body size. In: Ecology of Fishes on Coral Reefs (ed. Mora, C.). Cambridge University Press, Cambridge, UK, pp. 104-115.

Leibold, M.a., Holyoak, M., Mouquet, N., Amarasekare, P., Chase, J.M., Hoopes, M.F. et al. (2004). The metacommunity concept: a framework for multi-scale community ecology. Ecol. Lett., 7, 601-613.

Losos, J.B. \& Ricklefs, R. (2009). The Theory of Island Biogeography Revisited. Princeton University Press, Princeton, USA.

Luiz, O.J., Allen, A.P., Robertson, D.R., Floeter, S.R., Kulbicki, M., Vigliola, L. et al. (2013). Adult and larval traits as determinants of geographic range size among tropical reef fishes. Proc. Natl Acad. Sci. USA, 110, 16498-16502.

MacArthur, R.H. \& Wilson, E.O. (1963). An Equilibrium Theory of Insular Zoogeography. Evolution (N. Y)., 17, 373-387.

Marquet, P.A. \& Cofre, H. (1999). Large temporal and spatial scales in the structure of mammalian assemblages in South America: a macroecological approach. Oikos, 85, 299-309.

Marquet, P.A. \& Taper, M.L. (1998). On size and area: Patterns of mammalian body size extremes across landmasses. Evol. Ecol., 12, 127139.

Marquet, P.A., Navarrete, S. \& Castilla, J. (1990). Scaling population density to body size in rocky intertidal communities. Science, 250, $1125-1127$. 
Marquet, P.A., Quiñones, R.a., Abades, S., Labra, F., Tognelli, M., Arim, M. et al. (2005). Scaling and power-laws in ecological systems. $J$. Exp. Biol., 208, 1749-1769.

Mazel, F., Guilhaumon, F., Mouquet, N., Devictor, V., Gravel, D., Renaud, J. et al. (2014). Multifaceted diversity-area relationships reveal global hotspots of mammalian species, trait and lineage diversity. Glob. Ecol. Biogeogr., 23, 836-847.

Mazel, F., Renaud, J., Guilhaumon, F., Mouillot, D., Gravel, D. \& Thuiller, W. (2015). Mammalian phylogenetic diversity-area relationships at a continental scale. Ecology, 96, 2814-2822.

McMahon, T. (1973). Size and shape in biology. Science, 179, 1201-1204.

Millien, V. \& Gonzalez, A. (2011). The maximal body mass-area relationship in island mammals. J. Biogeogr., 38, 2278-2285.

Mora, C., Chittaro, P., Sale, P., Kritzer, J. \& Ludsin, S. (2003). Patterns and processes in reef fish diversity. Nature, 421, 933-936.

Mora, C., Aburto-Oropeza, O., Ayala Bocos, A., Ayotte, P.M., Banks, S., Bauman, A.G., et al. (2011). Global Human Footprint on the Linkage between Biodiversity and Ecosystem Functioning in Reef Fishes. PLoS Biol., 9, e1000606. DOI: 10.1371/journal.pbio.1000606.

Nash, K.L., Welsh, J.Q., Graham, N.A.J. \& Bellwood, D.R. (2015). Home-range allometry in coral reef fishes: comparison to other vertebrates, methodological issues and management implications. Oecologia, 177, 73-83.

Nee, S., Read, A.F., Greenwood, J.J.D. \& Harvey, P.H. (1991). The relationship between abundance and body size in British birds. Nature, 351, 312-313.

Newbold, T., Hudson, L.N., Hill, S., Contu, S., Lysenko, I., Senior, R. et al. (2015). Global effects of land use on local terrestrial biodiversity. Nature, 520, 45-50.

Okie, J.G. \& Brown, J.H. (2009). Niches, body sizes, and the disassembly of mammal communities on the Sunda Shelf islands. Proc. Natl Acad. Sci. USA, 106(Suppl), 19679-19684.

Parravicini, V., Kulbicki, M., Bellwood, D.R., Friedlander, A.M., AriasGonzalez, J.E., Chabanet, P. et al. (2013). Global patterns and predictors of tropical reef fish species richness. Ecography (Cop.), 36, 1254-1262.

Peters, R. \& Wassenberg, K. (1983). The effect of body size on animal abundance. Oecologia, 60, 89-96.

Rooney, N., Mccann, K.S. \& Moore, J.C. (2008). A landscape theory for food web architecture. Ecol. Lett., 11, 867-881.

Smith, F.A. \& Lyons, S.K. (2013). Animal body size: linking pattern and process across space, time, and taxonomic group. The University of Chicago, Chicago.

Srinivasan, U.T., Dunne, J.A., Harte, J. \& Martinez, N. (2007). Response of complex food webs to realistic extinction sequences. Ecology, 88, 671-682.

Stier, A.C., Hein, A.M., Parravicini, V. \& Kulbicki, M. (2014). Larval dispersal drives trophic structure across Pacific coral reefs. Nat. Commun., 5, 5575 .
Teh, L.S.L., Teh, L.C.L. \& Sumaila, U.R. (2013). A Global Estimate of the Number of Coral Reef Fishers. PLoS One, 8, e65397.DOI: 10.1371/ journal.pone.0065397.

Tscharntke, T., Tylianakis, J.M., Rand, T.A., Didham, R.K., Fahrig, L., Batary, P. et al. (2012). Landscape moderation of biodiversity patterns and processes - eight hypotheses. Biol. Rev., 87, 661-685.

Vucic-Pestic, O., Rall, B.C., Kalinkat, G. \& Brose, U. (2010). Allometric functional response model: body masses constrain interaction strengths. J. Anim. Ecol., 79, 249-256.

Warren, B.H., Simberloff, D., Ricklefs, R.E., Aguilée, R., Condamine, F.L., Gravel, D. et al. (2015). Islands as model systems in ecology and evolution: prospects fifty years after MacArthur-Wilson. Ecol. Lett., 18, 200-217.

White, E.P., Ernest, S.K.M., Kerkhoff, A.J. \& Enquist, B.J. (2007). Relationships between body size and abundance in ecology. Trends Ecol. Evol., 22, 323-330.

Whittaker, R.J., Rigal, F., Borges, P.A.V., Cardoso, P., Terzopoulou, S., Casanoves, F. et al. (2014). Functional biogeography of oceanic islands and the scaling of functional diversity in the Azores. Proc. Natl Acad. Sci. U. S. A., 111, 13709-13714.

Wieters, E.A., Gaines, S.D., Navarrete, S.A., Blanchette, C.A. \& Menge, B.A. (2008). Scales of dispersal and the biogeography of marine predator-prey interactions. Am. Nat., 171, 405-417.

Williams, R.J. \& Martinez, N.D. (2000). Simple rules yield complex food webs. Nature, 404, 180-183.

Williams, R.J., Anandanadesan, A. \& Purves, D. (2010). The probabilistic niche model reveals the niche structure and role of body size in a complex food web. PLoS ONE, 5, e12092.

Woodward, G., Ebenman, B., Emmerson, M., Montoya, J.M., Olesen, J.M., Valido, A. et al. (2005). Body size in ecological networks. Trends Ecol. Evol., 20, 402-409.

Yodzis, P. \& Innes, S. (1992). Body size and consumer-resource dynamics. Am. Nat., 139, 1151-1175.

\section{SUPPORTING INFORMATION}

Additional Supporting Information may be found online in the supporting information tab for this article.

Editor, David Storch

Manuscript received 9 September 2016

First decision made 20 October 2016

Manuscript accepted 14 November 2016 